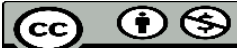

Licenciado sob uma licença Creative Commons

ISSN 2175-6058

https://doi.org/10.18759/rdgf.v19i2.1132

\title{
DIREITOS HUMANOS, TRANSFORMAÇÕES SOCIAIS E A RECONSTRUÇÃO DA MEMÓRIA SOBRE A DITADURA BRASILEIRA: REFLEXÕES A PARTIR DA COMISSÃO NACIONAL DA VERDADE
}

HUMAN RIGHTS, SOCIAL TRANSFORMATION AND THE RECONSTRUCTION OF THE MEMORY ON THE BRAZILIAN DICTATORSHIP: THOUGHTS FROM NATIONAL COMMISSION OF THE TRUTH

Luís Gustavo Gomes Flores

Ivo dos Santos Canabarro

\section{RESUMO}

O presente artigo propõe uma reflexão sobre a importância da construção de uma memória social como contribuição para a garantia dos Direitos Humanos, a partir da Comissão Nacional da Verdade (CNV) no Brasil. Conhecer o passado é fundamental para pensar um futuro melhor, por isso o trabalho indaga se a construção de uma memória social sobre a ditadura Civil Militar tende a encaminhar a questão para o perdão, a punição ou o esquecimento? Para tanto se utiliza do método hipotético-dedutivo, com a técnica de pesquisa monográfica e pesquisa bibliográfica. Trata-se de uma reflexão crítica sobre as eventuais repercussões do relatório da CNV e as possibilidades de aprendizado que ele proporciona.

Palavras-chave: Direitos Humanos, Memória Social, Comissão Nacional da Verdade 


\section{ABSTRACT}

This article proposes a reflection on the importance of building a social memory as a contribution to the guarantee of Human Rights, based on the National Commission of Truth (CNV) in Brazil. Knowing the past is fundamental to thinking about a better future. So the paper asks if the construction of a social memory about the Civil Military dictatorship tends to refer the issue to forgiveness, punishment or forgetfulness? For that, the deductive hypothetical method is used, with the technique of monographic research and bibliographic research. This is a critical reflection on the possible repercussions of the $\mathrm{CNV}$ report and the possibilities of learning that it provides.

Key words: Human Rights, Social Memory, National Commission of the Truth

\section{INTRODUÇÃO}

O presente texto busca desenvolver uma reflexão sobre a importância de uma revisão do que se conhece sobre o passado com a pretensão de seleção e conservação na história, sobretudo no que diz respeito ao período ditatorial brasileiro para a garantia, proteção e desenvolvimento dos Direitos Humanos. Essa reconstrução do passado pode ser compreendida simbolicamente como uma espécie de Memória, uma metáfora do Tempo para pensar a importância da Comissão Nacional da Verdade para os Direitos Humanos.

Convém considerar que, ao longo da história, o estudo dos Direitos Humanos vem sendo desenvolvido em contextos de múltiplas transformações sociais. Em alguns períodos essas transformações foram mais lentas, em outros mais rápidas e na atualidade estão ocorrendo de forma cada vez mais acelerada. Isto sugere certa observação do Tempo, no que diz respeito à certa tensão entre as dinâmicas de mudança e conservação. Nesse sentido, para compreender certos aspectos temporais dessa dinâmica, relevantes para os Direitos Humanos, convém observar a importância da Memória em face da sombra deixada por vinte e um anos de ditadura militar no Brasil.

Nessa perspectiva, o trabalho busca responder o problema de pesquisa que indaga se a relevância de reconstruir a Memória do período 
ditatorial no Brasil para os Direitos Humanos, através da Comissão Nacional da Verdade, tende a acentuar um caráter voltado ao Perdão, à Punição ou ao Esquecimento?

Num primeiro momento, como hipótese tem-se que a construção de uma Memória sobre o período ditatorial no Brasil através da Comissão Nacional da Verdade, na perspectiva dos Direitos Humanos, possui um caráter voltado ao Perdão, contudo, este deve ser compreendido enquanto uma "metáfora complexa", possível de ser elucidado através das contribuições de François Ost, embora se possa observar traços tanto de punição, como de esquecimento. O Perdão como parte de uma reflexão complexa sobre a produção jurídica e política do Tempo, na perspectiva de François Ost pode ser considerada como relevante para esclarecer as questões e perspectivas sugeridas pelo presente trabalho.

Assim, tem-se como objetivo investigar e desenvolver uma reflexão sobre a importância da Memória como metáfora do Tempo para as reflexões jurídicas no âmbito dos Direitos Humanos, sobretudo no que diz respeito ao trabalho de construção de uma forma de Memória através da Comissão Nacional da Verdade no Brasil.

Nesse sentido, o desenvolvimento do trabalho será apresentado em três momentos. Primeiramente, no ponto 2, intitulado Memória como metáfora do tempo para as reflexões jurídicas, foi desenvolvido um estudo voltado à elucidar o que se pode compreender com a ideia de Memória, bem como de sua importância como metáfora do Tempo para as reflexões jurídicas. Num segundo momento, no ponto 3, com o título A importância da CNV para a construção da Memória social e a correspondente valorização dos Direitos Humanos, buscou-se desenvolver um estudo direcionado, em especial, à construção e valorização da Memória em âmbito nacional brasileiro através da Comissão Nacional da Verdade. Como desfecho tem-se no ponto 4, intitulado de A Memória dos Direitos humanos e os anos de chumbo no Brasil, entre "perdão" e "condenação", a observação da importância da Comissão Nacional da Verdade e da construção da Memória para o desafio de pensar os Direitos Humanos na sociedade complexa, entre o dilema do perdão e condenação. Para tanto utilizou-se do método hipotético-dedutivo, com a técnica de pesquisa monográfica e bibliográfica. 
Portanto, a instituição da Comissão Nacional da Verdade significa um relevante espaço de reflexão na constituição da história e das identidades de todos que constituem o conjunto dos cidadãos brasileiros. Um passo fundamental para acentuar a importância pragmática das garantias, realizações e desenvolvimento dos Direitos Humanos no contexto brasileiro.

\section{MEMÓRIA COMO METÁFORA DO TEMPO PARA AS REFLE- XÕES JURÍDICAS}

Pensar a "Memória" sugere uma reflexão temporal sobre a dinâmica dos hábitos, acontecimentos e conhecimentos. (BACHELARD, 2007, p. 22). Sempre existem os que são lembrados e os que são esquecidos. Sendo assim, lembrança e esquecimento são importantes para a compreensão da Memória. Como toda representação da realidade, a dimensão semântica da Memória, dependerá do respectivo ponto de observação. (MATURANA, 2000, p. 61). Sendo a sociedade um ambiente com múltiplas perspectivas, o significado de Memória poderá assumir diversos contornos, conforme a perspectiva, que pode emergir de vários âmbitos como, por exemplo, da filosofia, sociologia, biologia, bioquímica, psicologia, neurologia, psiquiatria, informática e etc. (BRAGA, 2000, p. 23).

Apesar das múltiplas possibilidades de observação, é preciso partir de uma compreensão inicial. Assim, é possível afirmar que a Memória em sua significação mais elementar está relacionada predominantemente à certa capacidade de recordação de um indivíduo. ${ }^{1}$ Trata-se de uma concepção que inicialmente ganhou contornos predominantemente biológicos, acentuando o organismo do ser humano. Do coração ao cérebro, a ênfase foi colocada no interior do organismo que recorda. Nesse sentido, muitos estudos tratam a Memória como uma propriedade do indivíduo e aí como um processo puramente interno, no qual o material armazenado pode ser trazido à consciência. (BRAGA, 2000, p. 23).

Contudo, esse enfoque que acentua o biológico e o individual do ser humano que recorda, passou a ser questionado nas décadas de 20 e 30 por diversos autores, tanto na linha da sociologia francesa, passando pela psicologia inglesa, até a psicologia russa, que foram além, contemplando 
aspectos sócio-culturais na constituição da Memória (BRAGA, 2000, p. 10). Ou seja, a memória passa a ser compreendida a partir de uma elaboração que se dá em meio a dinâmica social. 0 ambiente social apresenta ressonâncias que são assimiladas mentalmente pelo ser humano que as auto-organiza no interior do seu sistema psíquico. (MATURANA;VARELA, 2001, p. 181).

A Memória não é uma reprodução pura e estática. 0 mais improvável é a ocorrência de uma recordação exata. Geralmente ela é o resultado de uma construção, que com o tempo pode sofrer mudanças, conter omissões, distorções e simplificações, em face de interesses, sentimentos e experiências da vida cotidiana. (BRAGA, 2000, p. 41). Recordação e criação são aspectos presentes no processo de elaboração da Memória.

Já o conteúdo será o resultado da equação entre o que é observado no ambiente social e o processo de elaboração interna do indivíduo, a partir de interpretação, tradução e reorganização de informações. Os estímulos da sociedade são articulados com a capacidade subjetiva de processar e assimilar isso juntamente com toda uma bagagem mental desenvolvida com as experiências ao longo da vida. (MATURANA, 2000, p. 61).

Nesse sentido, significa também que a Memória é um processo de construção através do qual são equacionados aspectos que emergem da estrutura biológica em simbiose com aspectos sociológicos e culturais, como uma construção social. Embora exista a dimensão individual de elaboração de certa Memória, o ser humano sempre está inserido em uma sociedade, em uma cultura, em um contexto histórico, de forma que a memória individual está imbricada com uma memória coletiva, que é mais ampla. (BRAGA, 2000, p. 51).

Embora se possa observar que em linhas gerais a Memória nos sugere certa ideia de referência ao passado e conservação de uma lembrança, trata-se de uma elaboração complexa. Por isso, interessa considerar aqui a Memória em seu aspecto simbólico, buscando observá-la como uma metáfora. Uma forma de pensar o que não existe mais no presente. Embora todo passado só pode ser recomposto no presente, o presente nunca pode comportar todo o passado. Nisso já se pode compreender que a elaboração da Memória pressupõe certa seletividade e equação entre recordação e esquecimento. (OST, 1999, p. 43). 
Por isso se considera que enquanto metáfora a Memória é uma forma de observação do Tempo, considerando certa articulação entre passado e presente. Contudo, como já mencionado, a Memória não é constituída por uma lembrança exata, que se repete fielmente na recordação. Logo, não pode ser simplesmente traduzida ou reduzida à ideia de repetição. Fala-se em construção da Memória, justamente porque ela é resultado de lembranças e criações. Em cada olhar, seja para o passado ou para o presente, se está reconstruindo versões do mundo.

Como uma metáfora do Tempo a Memória sugere simbolicamente um processo de constituição complexa, onde se realiza certa seleção do que se vai esquecer e o que se pretende recordar, ou seja, o que se pretende que fique conservado na "história". (OST, 1999, p. 51-52).

Não se pode recordar de tudo, assim como, também não se pode "não esquecer de nada". Por isso a dinâmica do Tempo permite que se observe a mudança, que por sua vez sugere certo contraste, entre o que era no passado e o que é "agora" no presente. É nessa perspectiva que se torna relevante essa metáfora do Tempo para desenvolver uma reflexão sobre as seleções jurídicas, a dinâmica de mudança e o contraste do resultado entre o antes e o depois, permitindo assim certa observação de uma possível perspectiva evolutiva do Direito. (BACHELARD, 2007, p. 42-43).

0 estudo sobre a Memória é de grande relevância para pensar garantias e o desenvolvimento dos Direitos Humanos, pois não deixa de ser uma forma de selecionar o que se deve "desligar", esquecer e evitar, ou por outro lado, o que se considera imprescindível e se deve conservar. Por isso a Memória pode servir como uma metáfora reflexiva para observar as possibilidades evolutivas do Direito. Ela será o resultado de certa capacidade de seleção que envolve esquecimento e lembrança. (OST, 1999, p. 51-52).

Ao mesmo tempo em que a Memória pode servir como uma metáfora reflexiva para pensar como o Direito se operacionaliza internamente ${ }^{2}$, ele também possui um papel fundamental no processo de constituição da Memória da Sociedade. Numa perspectiva mais estrutural da sociedade, se pode observar a Memória da sociedade como uma construção institucional, fruto de múltiplas perspectivas, principalmente a perspectiva jurídica. (ROCHA, 2003-a, p. 309). 
A Memória enquanto uma metáfora do Tempo interessa para compreender a importância simbólica da instituição temporal do Direito e da Sociedade. Segundo François Ost, o Direito é uma espécie de guardião da Memória da sociedade. (OST, 1999, p. 52). Embora o Direito deva sempre considerar a importância de pensar o passado, presente e futuro, tradicionalmente tem-se acentuado o passado de forma excessiva, tornando muito acentuada uma forma de operacionalização que ficou conhecida por dogmática jurídica. (ROCHA, 2003-b, p. 195). “O Direito é uma estrutura da sociedade e assim configura a continuidade e a descontinuidade da ação social na forma da sociedade dominante, até o Advento da globalização". (ROCHA, 2003-a, p. 312). Contudo, através de certa estratégia de antecipação aos problemas que possam ocorrer no futuro, busca evitar eventuais violações apresentando respostas jurídicas que já foram elaboradas no passado. Trata-se de expectativas normativas contrafáticas que buscam estabelecer certo controle do Tempo buscando fazer com que se repitam no presente posturas, significados e valores consagrados no passado, a fim de que se seja criado certa sensação de segurança em relação ao futuro. (ROCHA, 2003-b, p. 196).

Dessa forma, o Direito funciona como um guardião da Memória social, buscando conservar no Tempo certos padrões de comportamentos que se consideram juridicamente desejáveis, ou valores consagrados como, por exemplo, os Direitos Humanos. São conquistas reforçadas juridicamente para que sejam conservadas na Memória social. Apesar de as leis em si não conseguirem evitar a violação dos Direitos Humanos, pois funcionam como expectativas normativas (LUHMANN, 1983, p. 56), até mesmo eventual violação vem a reforçar a importância dos Direitos Humanos. Paradoxalmente eventuais violações dos Direitos Humanos, de certa forma, acentuam a sua importância que é reforçada por expectativas contrafáticas (LUHMANN, 1983, p. 57), representadas por normas jurídicas que determinam contra os fatos delituosos (que negaram tais direitos através de alguma violação), que deve prevalecer os valores de respeito, proteção, garantia e manutenção dos Direitos Humanos, que necessitam serem preservados juridicamente na dinâmica e na memória da sociedade. 0 próprio Direito à Memória, enquanto uma prerrogativa fundamental para o entendimento do papel dos atores sociais na atuali- 
dade é de grande relevância para que seja possível a garantia, realização e proteção dos Direitos Humanos na Sociedade atual. (CARVALHO, 2017).

Essa reflexão é fundamental para compreender a importância da Comissão Nacional da Verdade. Constituindo-se como uma forma de observação dos Direitos Humanos em certa reinstituição que equaciona traços do passado que se estendem no presente, sob uma sombra deixada por vinte e um anos de Ditadura Militar no Brasil.

\section{A IMPORTÂNCIA DA CNV PARA A CONSTRUÇÃO DA MEMó- RIA SOCIAL E A CORRESPONDENTE VALORIZAÇÃO DOS DIREITOS HUMANOS}

Para pensar os Direitos Humanos é fundamental que se possa realizar certa contextualização social, histórica e cultural. É importante compreender minimamente as trajetórias realizadas no passado como elementos constitutivos da Memória da Sociedade. (CANABARRO, 2014). Necessário para o presente é ser capaz de projetar possibilidades de futuro. Nesse sentido, a Memória por ser o resultado de uma equação complexa entre passado, presente e futuro, é imprescindível para a construção e afirmação de identidades individuais e coletivas. (OST, 1999, p. 45).

É a Memória Social que permite a cada indivíduo ou grupo dar sentido ao seu lugar no mundo. Ela está intimamente ligada a capacidade de autoconstrução, pois atores sociais precisam desenvolver suas identidades em uma dinâmica interdependente entre individual e coletivo. (OST, 1999, p. 52-53).

A garantia da Memória e do reconhecimento das identidades é fundamental em qualquer sociedade, uma vez que permite certa noção de pertencimento dos indivíduos e dos grupos. Constituem um rico conjunto de informações que revela aspectos mistos de memórias individuais e coletivas, desde perspectivas presentes nas subjetividades de relatos, como em Memórias oficiais, fundidas em relações de poder, bem como em sentimentos e reconhecimentos de pertencimento.

Convém mencionar que uma das tarefas mais árduas no estudo sobre a memória é o fato de que seja preciso alcançar dimensões imper- 
ceptíveis, ou seja, é necessário desvendar o desconhecido que pode estar encerrado no que se pode compreender como uma memória subterrânea. (POLLACK, 1989, p. 3-15). Em se tratando do contexto brasileiro e de uma observação específica sobre os anos de período ditatorial, pode-se mencionar que é a partir de um cuidadoso olhar sobre essa memória subterrânea que se pode identificar elementos importantes, como por exemplo, os respectivos atores sociais que sofreram torturas e mesmo os desaparecidos. ${ }^{3}$ Pessoas que foram "condenadas" por uma tradição repressiva a permanecerem no silêncio durante muito tempo, transportando uma dimensão da memória não-dita. Muitos se mantiveram calados por medo de expor e de reviver (mesmo que em sua subjetividade) as experiências traumáticas das torturas vividas. (POLLACK, 1989, p. 3-15). As memórias subterrâneas podem ser as mais complicadas de virem à tona, pois podem ser tão traumáticas que as pessoas preferem o silêncio, a menos que se encontre uma escuta confiável (LUHMANN, 1996) para que possam ser recompostas e compartilhadas.

Nesse viés é que se buscou instituir no Brasil, pela Lei n. $\stackrel{o}{-}$ 12.528/2011, uma Comissão Nacional da Verdade - CNV. Instituída pela Lei no 12.528/2011, trata-se de uma proposta de reconstituição das violações aos Direitos Humanos cometidas durante o período da ditadura militar. Tal proposta corresponde à formação de uma CNV responsável por investigar as violações de Direitos Humanos ocorridas entre os anos de 1946 e 1988, que compreende o período ditatorial no Brasil (19641985). Tratava-se de apurar certos fatos a fim de obter depoimentos e relatos no sentido de reconstruir a "verdade" histórica de forma democrática. Assumiu assim a tarefa de construir um percurso das memórias elucidando uma aproximação entre a questão teórica e metodológica até o encontro com as experiências vividas pelas pessoas que foram torturadas na ditadura militar. Num primeiro momento emerge a memória individual que, além dos relatos também está acondicionada nos suportes, tais como: fotografias, diários, cartas, documentos manuscritos ou impressos e demais formas de preservação de informações que são acumuladas ao longo da vida das pessoas.

A CNV, como forma de implementar a complexa construção da Memória sobre o período ditatorial brasileiro, consiste em um importante 
passo, voltado a incrementar os Direitos Humanos em uma sociedade dinâmica, fluída e líquida. (BAUMAN, 2001, p. 7-8). Todo o movimento desencadeado pela CNV constituiu-se como um espaço favorável para a comunhão de esforços no sentido de buscar romper obstáculos sociais, políticos e culturais, a fim de interromper um longo período de silêncio, elucidando inúmeras experiências traumáticas vividas por pessoas que lutaram contra o regime ditatorial no Brasil. 0 que se constrói sobre a ditadura militar no Brasil através da CNV é resultante de coragem e um grande esforço pela justiça que da força para a construção de um processo de revisão de estudos sobre a Memória, pois muito do que se produziu historicamente como memória oficial foi apenas fruto de construções parciais.

Parte do trabalho da CNV consiste na elaboração de um relatório, contendo dados sobre tortura e mortes de pessoas que lutaram contra o regime ditatorial no Brasil. Trata-se de um denso relatório, composto por três volumes ${ }^{4}$, trazendo detalhes e observações sobre casos de torturados, mortos e desaparecidos. Para tanto, a CNV foi responsável pela criação e realização de caravanas que percorreram todo o Brasil em busca de depoimentos de pessoas que foram torturadas e também familiares de vítimas desaparecidas. Os depoimentos dessas pessoas construíram novos contornos para certa Memória coletiva sobre a ditadura militar, que até então não se tinha conhecimento. As caravanas realizadas nos Estados tiveram apoios de diferentes instituições como a OAB (Ordem dos Advogados do Brasil), universidades e demais órgãos que trabalham em prol dos Direitos Humanos. (CANABARRO, 2014, p. 222).

Os estudos de casos apresentados no Relatório da CNV resultaram de pesquisas sistemáticas em todo o Brasil. Foram criadas várias subcomissões que através das caravanas em diversos locais do Brasil, buscaram colher depoimentos, materiais, considerados a partir de uma perspectiva quantitativa e qualitativa. Os depoimentos pesquisados foram sistematizados para possibilitar uma noção mais abrangente de casos investigados. As análises apresentadas são bem ilustrativas, trazendo dados numéricos e possibilitando uma noção, o mais próxima possível, do que foi a realidade dos acontecimentos. 
Foram realizadas audiências públicas em quatorze Estados, bem como a busca de documentos sobre a ditadura militar. Nessas audiências públicas eram convidadas pessoas que foram vítimas da ditadura, presos políticos, pessoas que foram torturadas e familiares de pessoas mortas ou desaparecidas. Também participaram pessoas ligadas aos Direitos Humanos. Os depoimentos colhidos nas audiências públicas foram fundamentais para a complementação das informações obtidas nas fontes escritas. Realizando-se um verdadeiro exercício de recomposição de uma memória subterrânea.

Em relação ao número de mortos contabilizados no Relatório da CNV, a obtenção deu-se a partir de dados oficiais dos inquéritos, pois não se pode considerar os casos omissos nas documentações obtidas. Muitas pessoas foram consideradas como desaparecidas, mas provavelmente foram de fato executadas e enterradas em cemitérios clandestinos, impossibilitando a elaboração de listas oficiais das mortes que permitisse revelar a real dimensão das atrocidades cometidas pelos militares nos anos de chumbo. Os casos de desaparecidos que constam no Relatório da CNV foram decorrentes de denúncias de familiares. A verificação de eventuais identificações dessas vítimas na atualidade demanda um processo muito lento do Estado em realizar a exumação das ossadas humanas encontradas nos cemitérios clandestinos, pois a grande maioria destes desaparecidos já devem estar mortos. Alguns desaparecidos foram para outros países. Muitos órgãos responsáveis por torturas e mortes trataram de destruir documentos oficiais. Suspeita-se que em muitos casos a documentação foi totalmente incinerada. Convém salientar, que a prática da tortura e mesmo as mortes foram feitas através de mecanismos e agentes do Estado.

Os depoimentos precisaram ser construídos através de uma escuta confiável para que relatos carregados de emoções e subjetividades pudessem ser cuidadosamente documentados e trazidos à público, revelando experiências traumáticas, que muitas pessoas passaram ao serem submetidas à tortura na ditadura militar. (LUHMANN, 1996).

Com a tarefa de tomar depoimentos e construir os relatos - foi criado a Clínica do Testemunho que realizou em todo o Brasil, um trabalho qualificado na coleta de depoimentos com o auxílio de psicólogos 
e psicanalistas, possibilitando assim uma escuta qualificada. Assim, os depoentes encontraram uma escuta segura, cuidadosa e confiável. Muitos nunca haviam falado sobre a tortura em público, pois tinham receio de retomar os seus traumas. Os depoimentos encontraram ressonância nos grupos que também tiveram uma possibilidade para compartilhar angustias e sofrimentos comuns.

Com o cruzamento de informações relevantes dos relatos, dos documentos e com a tabulação dos dados dos depoimentos, foi possível perceber que as pessoas que foram torturadas tinham muito a dizer. A documentação oficial existente é parcial, apenas contendo dados que "poderiam ser mostrados" segundo interesse dos militares que implementaram a ditadura. Todos os relatos produzidos constituem parte de um dossiê que complementa o Relatório da CNV. Trata-se de um trabalho de continuidade das ações implementadas, pois durante os dois anos de permanência da comissão não foi possível coletar todos os depoimentos. Nesse sentido, convém apresentar uma tabela que contem alguns desses dados que resultaram de dois anos de atividades da $\mathrm{CNV}^{5}$, em diversos Estados do Brasil.

Tabela 1 - Dados do Relatório da Comissão Nacional da Verdade

\begin{tabular}{l|c}
\multicolumn{1}{c|}{ Dados } & Quantificação \\
\hline Recomendações & 29 \\
\hline Mortos & 191 \\
\hline Desaparecidos políticos & 243 \\
\hline Audiências públicas realizadas pela CNV & 75 \\
\hline Depoimentos colhidos nas audiências públicas & 565 \\
\hline Estados que sediaram as audiências & 14 \\
\hline Laudos periciais & 21 \\
\hline Recomendações & 154,5714286 \\
\hline Mortos & 152,5714286 \\
\hline Recomendações & 150,5714286 \\
\hline
\end{tabular}




\begin{tabular}{l|c}
\multicolumn{1}{c|}{ Dados } & Quantificação \\
\hline Mortos & 148,5714286 \\
\hline Desaparecidos políticos & 146,5714286 \\
\hline Recomendações & 144,5714286 \\
\hline Mortos & 142,5714286 \\
\hline Desaparecidos políticos & 140,5714286 \\
\hline Audiências públicas realizadas pela CNV & 138,5714286 \\
\hline Depoimentos colhidos nas audiências públicas & 136,5714286 \\
\hline Estados que sediaram as audiências & 134,5714286 \\
\hline Laudos periciais & 132,5714286 \\
\hline Recomendações & 130,5714286 \\
\hline Mortos & 128,5714286 \\
\hline Recomendações & 126,5714286 \\
\hline Mortos & 124,5714286 \\
\hline Desaparecidos políticos & 122,5714286 \\
\hline Recomendações & 120,5714286 \\
\hline Mortos & 118,5714286 \\
\hline Desaparecidos políticos & 116,5714286 \\
\hline Audiências públicas realizadas pela CNV & 114,5714286 \\
\hline Depoimentos colhidos nas audiências públicas & 112,5714286 \\
\hline Estados que sediaram as audiências & 110,5714286 \\
\hline Laudos periciais & 108,5714286 \\
\hline Recomendações & 106,5714286 \\
\hline Mortos & 104,5714286 \\
\hline
\end{tabular}

O Relatório da CNV possibilita recompor um conjunto significativo de informações que remetem às memórias subterrâneas, que geralmente guardam traumas, sofrimentos, ressentimentos e recalques que as pes- 
soas reprimiram. Um longo período de silêncio foi rompido por todo o processo de constituição do Relatório da CNV, que liberta lembranças aprisionadas e desejos de falar por muito tempo oprimidos, possibilitando conhecer, através de um delicado processo de escuta documentada, com detalhes das experiências de pessoas torturadas.

A partir dos trabalhos da CNV começou a ocorrer o empoderamento de vítimas que passaram a ter coragem de dar o seu relato. Isso é fundamental para a elucidação de uma memória subterrânea sobre a tortura no Brasil e sobre uma consciência mais qualificada sobre a importância de uma compreensão mais autêntica sobre essa parte da história brasileira.

Os depoimentos são emblemáticos e dão conta de recompor importantes relatos de uma memória subterrânea. Para muito além dos dados numéricos apresentados, um dos aspecto mais relevantes foi a capacidade que esse trabalho teve de desvendar as memória subterrâneas, possibilitando para as vítimas reelaborar pessoalmente de forma construtiva sofrimentos que tinham sido "guardados" durante muito tempo. 0 espaço de confiança e a coragem das vítimas se desenvolveu em uma simbiose que permitiu a exposição pública de fatos ocorridos e experiências vividas. (POLLACK, 1989, p. 3-15). Um passado de violações à Dignidade Humana que havia ficado não dito, impedindo, muitas vezes, que as pessoas dessem continuidade de forma minimamente normal às suas vidas, finalmente ganhou espaço, luz e amplificação através da CNV. (POLLACK, 1989, p. 3-15).

Começa-se a determinar o fim de certos ocultamentos e de sofrimentos que estavam encarcerados pelo medo. A repressão foi tão intensa durante a ditadura militar brasileira que as pessoas que sofreram torturas ficaram por muito tempo em silêncio. Num primeiro momento a estratégia de "esquecer" era uma forma de se colocar longe de todo um conjunto de recordações de ressentimentos e sofrimentos. Muitas famílias brasileiras tinham até vergonha de ter um de seus parentes torturados, com medo da segregação, já que os indivíduos considerados subversivos eram discriminados socialmente por aqueles que "não possuíam memória", ou a possuem de forma distorcida. Os traumas foram tão grandes que o esquecimento parecia a melhor alternativa encontrada 
para dar continuidade as suas vidas. Em algumas famílias falar da tortura era assunto proibido dentro de casa.

Esse foi um aspecto que indica que os anos de chumbo embora tenham de fato acabado ainda tiveram seus efeitos nocivos prolongados pelo tempo, muitas vezes comprometendo significativamente, se não a vida, a qualidade da vida de muitas vítimas e seus familiares. Isso tudo significa uma pesada carga histórica que desencadeia uma avalanche de sentimentos que se dividem entre o desejo de condenação, vingança ou o sentimento de perdão. Um processo de elaboração social que clama pela realização da justiça que muitas vezes, mesmo inconscientes se cristalizam na garantia, realização, desenvolvimento e proteção dos Direitos Humanos.

\section{A MEMÓRIA DOS DIREITOS HUMANOS E OS ANOS DE CHUMBO NO BRASIL, ENTRE “PERDÃO” E “CONDENAÇÃO”}

Resgatar os acontecimentos da ditadura implicam em despertar uma multiplicidades de sentimentos. Contudo, para além do sentido individual interessa o que vigora na sociedade enquanto construção coletiva, no que diz respeito a quais as ideias e valores ganham predominância. Para compreender isso convém considerar a contribuição de Le Goff (1996), para quem a Memória Coletiva não deixa de ser um instrumento de poder. Um poder que é exercido socialmente, inclusive sobre a concepção institucional do Tempo, que estabelece: o que deve ser preservado oficialmente na lembrança da sociedade? Por quanto tempo? E a quem prioritariamente interessa essa narrativa?

É nesse último sentido que o Direito está particularmente relacionado à concepção de Memória, enquanto uma forma de representar juridicamente o que se deve conservar e esquecer na sociedade. (OST, 1999, p. 55). Em grande medida o Direito exerce esse papel que, em geral, implica em esquecer práticas e posturas obsoletas, conservando as conquistas e garantias, sobretudo no que diz respeito aos Direitos Humanos.

Essa tarefa não é fácil, pois a memória social deve ser constituída em meio a certa tensão entre grupos sociais que buscam reconhecimento, 
espaço e a própria legitimação. Por isso, retomando Le Goff (1996), se entende que a construção social da memória sempre pressupõe um jogo de poder. (GOFF, 1996).

Grupos que possuem mais poder na sociedade, tradicionalmente possuem espaço, reconhecimento e com isso conseguem garantir a sua narrativa como Memória. Muitas vezes, embora a Memória figure como memória de uma coletividade, ela resulta da imposição ou predominância de um grupo específico que tem mais poder para fazer valer a sua narrativa. (FOUCAULT, 2008 p. 149). Os grupos mais vulneráveis e menos favorecidos, muitas vezes, precisam de politicas públicas para obter reconhecimento e espaço e, muitas vezes, ficam à margem ou até excluídos da história. Assim, cabe ao Estado garantir a representação equitativa de todos na constituição da Memória social. Contudo, as relações de poder atravessam os contornos do Estado e com isso, tradicionalmente minorias continuam desfavorecidas, sem acesso a um espaço igualitário pertencente à Memória oficial, o que consequentemente significa ser esquecido e estar invisível na construção histórica. (CANABARRO, 2014).

É no centro dessa tensão que a CNV revela a sua importância. Tendo um valioso papel de evitar qualquer desequilíbrio e invisibilidades na construção da Memória social brasileira, sobre o período entre os anos 1946 e 1988 (compreendendo a ditadura brasileira ocorrida entre 1964 e 1985). Trata-se de um esforço para que a Memória oficial resulte da equação de jogos de poder, mas que seja construída de forma plural, democrática e legítima.

Todo o processo de construção de Memórias é sempre realizado a partir da referência a uma realidade compartilhada socialmente que foi vivida ou imaginada ${ }^{6}$, seja no âmbito de cada particularidade ou coletividade. Para Halbwachs (2004), existe essa inevitável relação entre o individual e o coletivo. ${ }^{7}$ Muitas das lembranças individuais são também lembranças do grupo.

A Memória coletiva, além de ser dinâmica, constitui uma dimensão mais global dos acontecimentos. Nesse sentido, para Nora (1993), existe sempre a problemática dos lugares. A Memória é sempre esfacelada. Existe um pouco em cada lugar. ${ }^{8}$ Seus contornos são constituídos no espaço-tempo em tais lugares, na medida em que estes passam a ser 
contemplados. 0 autor enfatiza que a Memória se enraíza nos diferentes espaços, no concreto, nos gestos, nas imagens e nos diversos objetos. Esses são suportes onde podem ancorar os significados da Memória, abrigando os desdobramentos das representações elaboradas pelos indivíduos e grupos em constante processo de ajustamento.

Assim, a Memória Coletiva é um dos pontos cruciais das sociedades contemporâneas, pois ela possibilita a construção de uma "identidade oficial". Indivíduos e grupos buscam construir os elementos que definem suas identidades nos diferentes desdobramentos da Memória Social. Para Hall (2001), as identidades no mundo pós-moderno podem ser classificadas como múltiplas e, ao mesmo tempo, contraditórias, manifestadas sempre através de uma multiplicidade cultural que precisa ser observada em toda sua riqueza.

A Memória não deixa de ser uma "arte da narração", através da qual se busca recompor todo um campo de saberes sobre experiências, personagens, lugares (alguns sagrados), tramas e jogos de poder. Nas narrativas emergem relatos que transportam tramas discursivas, arranjos mitológicos, ocultações do que não se quer explicitar e etc. Os relatos geralmente são construídos arbitrariamente, com muitos aspectos ocultos, carregados de emoções e lembranças traumáticas. Por isso a construção da Memória desenvolvida pela CNV exige um cuidadoso processo interpretativo para elucidar o que realmente aconteceu entre o que foi relatado, ocorrido, imaginado ou ocultado.

Como já mencionado, talvez o mais delicado desse processo seja garimpar aquilo que está não-dito, que está aprisionado no âmbito mais profundo das subjetividades: a memória subterrânea..$^{9}$ Aquela Memória que está escondida na mais profunda subjetividade das vítimas, silenciadas pelo medo e opressão. Segundo Pollak (1989), a memória subterrânea é aplicada à Memória Coletiva, é um conceito-chave para o entendimento dos desafios da Memória no mundo contemporâneo. Marginalizadas, algumas minorias sociais só se fazem existir na sociedade através do compartilhar de sua história, geralmente de forma oral, onde a memória subterrânea encontra vazão. Muito do que se recupera a partir dela não se encontra registrado numa documentação escrita. São memórias de pessoas comuns, de minorias, das classes dominadas e oprimidas, pers- 
pectivas que normalmente não estão contempladas em uma memória oficial. Grandes dimensões das memórias subterrâneas permaneceram ocultadas durante muito tempo, pois, para emergir, necessitam de uma escuta segura e confiável, que se sobreponha ao receio de ameaça, risco ou simplesmente o medo. (POLLAK, 1989).

O motivo de haver memórias subterrâneas já sugere o sintoma de uma herança repressiva. 0 próprio poder institucional criou mecanismos de controle da Memória. Durante muito tempo documentos oficiais foram sonegados e obstáculos burocráticos foram colocados em prejuízo de maior transparência. Por isso é sempre importante questionar se a documentação que foi disponibilizada, depois de muita resistência, tenha passado por um filtro sobre o que deva ser a "verdade" conveniente. Em razão disso, já se pode imaginar que existem inúmeros limites para o que se pode pesquisar e conhecer no que diz respeito ao tema.

Paira assim uma atmosfera de suspeita sobre a disposição de construir verdadeiramente a memória por parte do Estado. Contribui ainda mais para essa percepção, tanto a Lei da Anistia, que corresponde à Lei no 6.683, de 28 de agosto de 1979, que afastou a responsabilização penal dos envolvidos em crimes cometidos no período da ditadura brasileira por agentes do Estado, como também o julgamento improcedente pelo Supremo Tribunal Federal (STF), no ano de 2010, da Ação de Arguição de Descumprimento de Preceito Fundamental (ADPF) no 153, que sustentava a não recepção da Lei da Anistia pela Constituição da República Federativa do Brasil de 1988.

Os anos entre 1964 e 1985 no Brasil foram anos de arbitrariedade, violência e terror. 0 menor dos ônus aos agentes do Estado envolvidos em crimes e violações de Direitos Humanos talvez seja o de viver com essa mancha na Memória social. ${ }^{10}$ Um ônus que decorre da reconstrução de uma "verdade histórica", que é Direito de toda a coletividade. Uma história que sempre esteve viva para vítimas e familiares que carregam a dor, o sofrimento, o trauma e a saudade de familiares e amigos desaparecidos.

São muitos e variados os sentimentos que emergem quando se pensa em um período marcado por torturas e mortes clandestinas como ocorreu na ditadura brasileira. 0 que não pode acontecer é um esquecimento obrigatório de um passado repleto de violações aos Direitos Humanos. 
(OST, 1999, p. 162). Nesse sentido, o que resta é a reconstrução da "verdade histórica'. Um registro da história ressignificada, não só para fazer um mínimo de justiça simbólica com as vitimas e seus familiares, mas também para que esse Direito à verdade histórica sirva de elemento pedagógico para futuras gerações. (CARVALHO, 2017). Para tanto, se pretendeu desenvolver uma organização para resgatar fatos que ocorreram no período da ditadura, buscando esclarecer uma parte da história negligenciada na constituição cultural e histórica do Brasil. Um primeiro passo foi a criação da Lei no 12.528 , de 18 de novembro de 2011, que ficou conhecida como Lei da Comissão Nacional da Verdade.

Pode-se compreender a proposta da CNV como uma forma de exercer o Perdão enquanto uma maneira de pensar o passado seletivamente, para então pensar o presente e o futuro de forma mais evolutiva. Para compreender essa perspectiva convém recordar que no desenvolvimento da civilização humana, houve o tempo em que muitos dos problemas eram resolvidos a partir do que se conhecia como autotutela, uma prática conhecida popularmente através do ditame de fazer justiça com as próprias mãos. Uma forma violenta de resolver conflitos que jogava a todos em um ciclo vicioso de vingança. Simbolicamente se pode pensar que o rompimento desse ciclo vicioso se deu a partir do momento em que a sociedade através do Direito foi capaz de realizar o "Perdão", que simboliza um momento de amadurecimento do Direito representando a instituição de certa capacidade evolutiva. Nesse sentido, simbolicamente o Perdão é um incremento para as reflexões jurídicas que permite melhor compreender a importância da CNV. (FLORES, SCHWARTZ, 2012).

A tarefa da CNV de enfrentar uma das maiores machas na história brasileira, que corresponde a um período ditatorial, marcado pela perda de direitos, autoritarismo e diversas violações aos Direitos Humanos. Esse cenário de intensa violência, repressão política, tortura e assassinatos, desperta inúmeros sentimentos. Talvez o mais provável seja um desejo de justiça, que pode ser associado à Vingança ou ao Perdão. Por compreender que o Perdão (OST, 1999, p. 43) talvez seja a saída mais evolutiva, interessa-nos aprofundar essa perspectiva relacionada aos Direitos Humanos. 
O significado reflexivo do Perdão ganha espaço com François Ost que se utiliza de quatro metáforas para pensar o Tempo do Direito, sendo que entre elas se pode encontrar o Perdão e a Memória. (OST, 1999, p. 43). Trata-se de uma estratégia simbólica para compreender a articulação do Tempo na operacionalização do Direito. A Memória está relacionada à necessária conservação operacionalizada pelo Direito, uma conservação que se articula com a operacionalização do Perdão. ${ }^{11}$ O Perdão para Ost é uma forma de desligar o passado, mas não de uma forma ingênua e simplista. Trata-se de um processo reflexivo de seleção sobre o que é considerado indesejado ou obsoleto e deve ser, portanto, desligado. (OST, 1999, p. 174).

Mas como o Perdão pode ser considerado na compreensão da proposta da CNV no contexto brasileiro? Compreendendo-o não como mero esquecimento obrigatório, com o intuito de esconder o que aconteceu, ocultando os aspectos reprováveis e dificultando a conscientização das gerações futuras, como se poderia imaginar em uma simples lei de anistia. (OST, 1999, p. 182). ${ }^{12}$ Trata-se de compreender o Perdão como certo enfrentamento do passado enquanto desligamento seletivo e construtivo. Um passado revisitado, revisado e democraticamente seletivo que ganha uma tônica de conciliação dada pelo significado social de Perdão. (OST, 1999, p. 153).

O Perdão simbólico deve ser operado na CNV de forma correspondente à experiência da África do Sul após o termino do Apartheid, que resolveu enfrentar o trauma social olhando diretamente para o passado a fim de superá-lo. Assim, na África do Sul ao criarem grupos de trabalho nos moldes da CNV no Brasil, atribuiu-se a denominação de Comissão de Verdade e Reconciliação. (OST, 1999, p. 187). Significa que a CNV no Brasil (Lei no 12.528/2011) deve ter um caráter democrático, revisor e reconciliador. Contudo, entre esses aspectos trata-se de acentuar o propósito de reconciliação, que deve se sobrepor a qualquer sentimento de vingança. Isso mostra a disposição de seguir em frente sem ignorar o sofrimento vivido, construindo certa consciência sobre a verdade histórica, a fim de evitar que, fatos como os dos anos de chumbo, venham a se repetir no futuro. (CANABARRO, 2014, p. 228). Acentua-se o signi- 
ficado de uma pedagogia construtiva na construção da paz social sem negligenciar o passado.

Esse exercício é de grande importância em todas as situações de violações de Direitos, havendo ou não punição, pois os efeitos meramente jurídicos e formais podem ser burocraticamente "apagados", mas o peso dos fatos sociais nas Memórias, sejam elas memórias subterrâneas ou não, permanece latente nas mentes das vítimas e na cultura social. Convém refletir profundamente nas palavras de Jeanne Marie Gagnebin que alerta sobre o não enfrentamento necessário do um passado que nos assombra.

Esse passado que insiste em perdurar de maneira não reconciliada no presente, que se mantém como dor e tormento, esse passado não passa. Eleressuscita de maneira infame nos inúmeros corpos torturados e mortos,mortos muitas vezes anônimos, jogados nos terrenos baldios ou nas caçambas de lixo, como foi o caso dos três jovens do morro da Providência no Rio, em julho de 2008 . 0 silêncio sobre os mortos e torturados do passado, da ditadura, acostuma a silenciar sobre os mortos e os torturados de hoje. (GAGNEBIN, 2010, p. 185).

Não se pode perder a sensibilidade com a vida, ou seja com a importância do seu significado. A omissão e insensibilidade diante de um passado difícil de ser enfrentado pode corresponder à certa conivência ou conformidade com a possibilidade passiva da "vida nua", com a banalidade da vida digna que também depende de uma memória libertadora. (AGAMBEN, 2004, p. 14-15).

Nesse sentido reside a importância de saber articular Memória e Perdão a partir da ideia de reconsciliação, pode significar certa libertação do passado, a partir do rompimento com a tradição de uma construção parcial da Memória que aliena o povo de sua própria história. (OST, 1999, p. 43). Essa alienação cria uma condição de vulnerabilidade na sociedade, produzindo uma cidadania manipulada, que mostra traços de cegueira, em relação à situações que colocam em risco o desenvolvimento dos Direitos Humanos. Incapaz de reconhecer o passado de terror, caso volte a se deparar com "ele". ${ }^{13}$ Por isso o não enfrentamento adequado dos fatos ocorridos no período entre os anos de 1964 e 1985, equivale a manter o fantasma da ditadura adormecido, mas também da possibilidade 
dele despertar a qualquer momento. Assim, negligenciar uma produção qualificada da Memória, implica em criar as condições para a produção de uma profunda alienação, que impacta drasticamente na construção e manutenção de garantia, realização e proteção dos Direitos Humanos.

Por isso convém destacar a importância de se reconstruir a Memória e a história brasileira, sobretudo, no período de ditadura, de forma a garantir certa tomada de consciência num processo educativo sobre a importância dos Direitos Humanos. Isso possibilita evitar erros já cometidos e criar certa consciência sobre os sacrifícios e dificuldades enfrentadas na conquista dos Direitos que se tem hoje. A Memória permite saber que não há garantias de não retrocesso, o que exige cuidado constante com a manutenção e desenvolvimento dos Direitos Humanos, para que estes contemplem as gerações futuras, buscando sempre elevar o nível de aprimoramento. Para tanto, o Direito à "verdade histórica" é fundamental para se buscar a realização dos Direitos Humanos hoje, como uma promessa que deve servir de motivação inclusive para a construção de requestionamentos, mas, sobretudo, para a construção de um futuro melhor. (CANABARRO, 2014, p. 228).

Assim, a CNV possui uma grande relevância na construção de condições para que futuras gerações não venham a absorver informações equivocadas sobre esse contexto histórico, mas sim estejam cientes da importância, tanto da Memória como do Perdão na garantia, realização e proteção dos Direitos humanos.

\section{CONCLUSÃo}

Considerar um cenário histórico marcado por um triste período ditatorial, a partir de uma observação localizada no contexto fluído e dinâmico da Sociedade atual, sugere a grande importância que deve ter Memória. Contudo, também se torna importante considerar a complexidade humana e social, bem como, a necessidade de referenciais consistentes, que por sua vez pressupõe compreender os limites de sentidos autorizados que determinam os contornos do mundo. Essa observação pode revelar a lógica de instituição a partir de certas relações de poder. É 
nessa perspectiva que se pode observar a importância de compreender os limites semânticos da Memória Social e de saber como esses limites foram construídos. Quando se está considerando o contexto social, observa-se que estabelecer esses limites deve ser uma tarefa coletiva, mas que não está dissociada do individual. A memória individual se constitui em uma ambivalência interdependente entre o singular e o coletivo, sendo de grande importância para a constituição da Memória da sociedade (uma espécie de memória oficial) que está subjacente na história.

Um dos grandes problemas que chama atenção, embora esteja não dito, foi a instituição de uma Memória da Sociedade brasileira a partir de relações de poder que ocultou uma parte significativa das lembranças, deixando à margem, ou até mesmo excluídas, as vozes de muitas vítimas desse regime opressor e uma respectiva lacuna na história.

Essa lacuna se constitui em um grave obstáculo para que gerações futuras conheçam os processos que culminaram em todo um regime de opressão e, portanto, possam em outros tempos reconhecer, os mais singelos e aparentemente despretensiosos traços de tendências à políticas autoritárias e assim buscar evitar.

No caso do Brasil isso é construído com certo apoio do Estado, na medida em que no ano de 1979 a Lei da Anistia (Lei no 6.683/79) afastou qualquer possibilidade de responsabilização penal de seus agentes, pela prática de crime praticado no período ditatorial brasileiro. No mesmo sentido, outro episódio semelhante foi no ano de 2010, em que o Supremo Tribunal Federal negou a revisão da Lei da Anistia, julgando improcedente a ADPF $\mathrm{n}$ - 153, recusando a tese de inconstitucionalidade da Lei da Anistia, que por ser incompatível com a Constituição Federal de 1988, não teria sido recepcionada por ela.

Tudo isso contribuiu de forma significativa para deixar parte da história brasileira no escuro. Não ter acesso a uma parte perversa da história brasileira pode significar um perigoso fator de ignorância e alienação, que compromete o desenvolvimento de uma cidadania mais lúcida, voltada a construir continuamente um mundo melhor. Assim, acentua-se aqui uma dúvida que paira no ar: imaginar qual a complexidade da intencionalidade por traz das estruturas do Estado brasileiro que levaram ao processo de 
tomada de tais decisões. Por isso, é de grande relevância desenvolver certa lucidez sobre a memória social brasileira.

Notadamente, os fatos ocorridos no período ditatorial foram extremamente graves. Em que pese os responsáveis não respondam penalmente pelos crimes cometidos, não parece razoável que eventualmente tenham o direito de se esquivar do olhar da sociedade. 0 mínimo que se pode esperar é que exista transparência e que os envolvidos arquem com o ônus de uma reprovação social. Este é um ônus irrisório perto do trauma e da saudade que, além de reconfigurar vidas inteiras, muitos foram condenados a carregar uma pesada carga de sentimento pelo resto da existência.

Em contrapartida, um movimento positivo nesse contexto foi a criação de uma Comissão Nacional da Verdade, através da Lei no 12.528/2011, com a tarefa de resgatar uma parte da Memória (e da história) que, em grande medida, foi convenientemente deixada de lado por forças que deixam certa suspeita sobre a existência de certo interesse em que a realidade da ditadura não viesse à tona.

Trata-se da proposta de elaboração de uma comissão voltada a realizar um minucioso e delicado trabalho de identificação e escuta de testemunhos de vítimas do regime militar, no sentido de contribuir para a reconstrução de uma "verdade" histórica de forma democrática. Trata-se de buscar contemplar uma multiplicidade de perspectivas que constitui a sociedade, sem a exclusão de grupos vulneráveis. Um espaço favorável para compartilhar sentimentos, informações e solidariedade, a fim de romper obstáculos sociais, políticos e culturais, criando as condições necessárias para o empoderamento de uma fala que consegue romper o silêncio e desencadeia movimentos.

Essa reflexão diz respeito tanto à certa preocupação com a constituição de uma Memória individual (que em grande medida também é social, já que é forjada em um contexto cultural e histórico), como também em relação a uma Memória Coletiva, forjada democraticamente.

Pode-se observar que a tarefa da CNV se constitui em um trabalho de grande cuidado para criar as condições mais adequadas de escuta confiável. Um processo lento até que as vítimas sintam-se confortáveis e ao compartilhar seu testemunho em uma rede de relatos, passem a in- 
centivar o empoderamento de muitos outros que ainda permanecem em silêncio. Um trabalho de sensibilidade para saber não apenas identificar e articular informações lembradas, imaginadas ou criadas, mas também parte da Memória ocultada, como uma memória subterrânea que repousa muitas vezes, na profundidade da subjetividade das vítimas e familiares, até que através da CNV pode ser resgatada.

Os relatórios elaborados pela CNV são importantes contribuições para ressignificar os contornos da história. Trata-se de uma relevante pesquisa, recuperando memórias subterrâneas, contendo a quantificação e descrição dos casos de torturas, mortes e desaparecimentos em todo o Brasil. Embora ainda parciais os dados levantados, são reveladores de vivências que não estavam contemplados em documentação oficial. Podendo servir de fonte para muitos cientistas sociais desenvolverem outros trabalhos que possam vir a somar na tarefa de esclarecimento e melhor observação dos fatos.

Nesse sentido, pode-se compreender que os Direitos Humanos constituem a dimensão de uma Memória produzida pelo Direito, enquanto conservação de valores que se deseja mantê-los no Tempo. Contudo, essa reflexão possibilita a emergência de uma dimensão complementar do passado e da Memória, que poderia fazer referência aqui à ideia de promessa, sugerindo a ligação com o futuro, já que os Direitos Humanos precisam ser garantidos, aprimorados e protegidos no presente e no futuro. Essa reflexão é de extrema relevância para pensar os Direitos Humanos, tanto para evitar com que problemas do passado possam voltar a se repetir.

0 resgate de uma memória traumática, também traz uma dimensão pedagógica construtivista para evitar erros já vivenciados. A Memória foi fundamental para o entendimento dos sofrimentos que as pessoas passaram sendo submetidas à torturas, bem como dos familiares que tiveram pessoas desaparecidas durante a ditadura. Essas experiências muitas vezes desenvolveram traumas que não são tão fáceis de superar, passando então as vítimas a desenvolver estratégias para aprender a conviver com isso. Por mais que haja alguma forma de reparação, ela sempre será parcial.

No âmbito pessoal é razoável imaginar que pode emergir os mais variados entendimentos ou interpretações de justiça, desde a identifica- 
ção dessa com certa expectativa de revanche, como também através da construção de um futuro consolador e reconciliado. No âmbito coletivo, talvez uma alternativa para desenvolver esse processo catalizador das expectativas e sentimentos seja a ideia de Perdão como uma metáfora que simboliza um momento de maturidade do Direito, que se afasta de perspectivas acentuadamente voltadas à vingança e possibilitam pensar um Direito mais construtivista.

Num contexto aonde o Estado afasta a responsabilidade penal dos responsáveis (agentes do Estado) é conveniente considerar que o Perdão, do ponto de vista individual, emotivo e sentimental é um aspecto que não há como mensurar. Em muitos casos se exigiria para tanto o reconhecimento dos militares envolvidos. Uma espécie de confissão, de preferência acompanhada de certo arrependimento, que serviria como um testemunho para contribuir com a construção da Memória. Esse não reconhecimento das violações cometidas pelos agentes das forças armadas (com raras exceções), talvez seja um dos grandes obstáculos para se evoluir nessa questão.

Talvez uma alternativa seja a estratégia de compreender o Perdão de forma simbólica, como uma metáfora para pensar uma forma seletiva de desligar o passado, no sentido de criar algumas condições evolutivas para que se possa seguir em frente. Um perdão simbólico para pensar certa operacionalização do Direito na produção de sua dinâmica temporal, correspondente à produção de uma Memória que, sem desconsiderar o ocorrido, seja libertadora das tristes lembranças de repressão do período da ditadura.

Trata-se de uma forma de fazer com que os Direitos Humanos prevaleçam, como uma forma de superação dos traumas do passado e como uma promessa de construção de certa consciência social. A importância da construção de uma Memória como metáfora para reflexões sobre os Direitos Humanos, através da Comissão Nacional da Verdade no Brasil não descarta certo esquecimento. Isso ocorre de forma programada através de um Perdão simbólico que seletivamente permite compreender o que se deve esquecer e o que se deve conservar para o futuro. Aqui se exige atenção, pois essa seletividade precisa ser fruto de uma construção coletiva e democrática da Memória social. Nesse sentido, Gagnebin ao 
falar sobre o pensamento de Walter Benjamin sobre a história, menciona que "sob a aparência da exatidão científica (que é preciso examinar com circunspecção), delineia-se uma história, uma narração que obedece interesses precisos". (GAGNEBIN, 1998, p. 215). Este é o cuidado que deve se ter na reconstrução da história, onde a memória é uma metáfora de resgate temporal.

Essa memória social como metáfora do tempo, representando o que deve ser conservado como lembrança é fundamental para o aprendizado jurídico-social. É com práticas como as proposta pela CNV que se pode compreender a importância de se ter atenção constante com a construção da memória, com o aprendizado social e jurídico. Uma espécie de afirmação de que algumas práticas que possam ofender os Direitos Humanos não devem ser necessariamente esquecidas, mas simbolicamente deixadas no passado, marcado sempre pela celebração de práticas contrárias e favoráveis à valorização da realização, respeito e proteção dos Direitos Humanos.

Foi preciso criar uma Comissão Nacional da Verdade (CNV) no Brasil para que os estudos fossem aprofundados, o que desencadeou a possibilidade de valiosos resultados. Embora a CNV esteja afastada da pretensão de processar e punir torturadores, busca-se em sua atuação a reconstrução de uma verdade mais autêntica sobre o que aconteceu durante a ditadura no Brasil. Trata-se de um trabalho ainda muito recente, mas de grande importância, já que sugere a continuação das investigações para que se venha a ter progressivamente maior elucidação dos acontecimentos e consequentemente uma melhor compreensão da importância dos Direitos Humanos enquanto uma Memória que se articula através do Perdão com uma Promessa de um mundo melhor. 


\section{Notas}

1 Convém mencionar que, de certa forma, estar ligada à capacidade de recordação (predominantemente) não exclui a simultânea relação com a ideia de esquecimento, que por sua vez não deve ser considerada aqui a partir de uma concepção ingênua e simplista.

2 Convém considerar a concepção de Maturana e Varela, de que "tudo que se observa depende do observador" (MATURANA, 2000, p. 61). Significa que a construção de uma observação depende de suas estruturas internas que são forjadas a partir de situações já ocorridas ou de experiências já vividas em uma dada sociedade, cultura e contexto histórico. Essas mesmas estruturas internos possibilitam a construção da Memória. É a partir dela que se pode remontar o passado e desenvolver as condições para compreender o presente e pensar o futuro.

3 Para obter maiores informações, consultar o Relatório III da Comissão Nacional da Verdade que traz dados sobre mortos e desaparecidos, assim como as informações contidas entre os capítulos 7 e 12 da parte III do Volume I do Relatório da Comissão Nacional da Verdade que compreendem os seguintes temas: Capítulo 7 - Quadro conceitual das graves violações; Capítulo 8 - Detenções ilegais e arbitrárias; Capítulo 9 - Tortura; Capítulo 10 - Violência sexual, violência de gênero e violência contra crianças e adolescentes; Capítulo 11 - Execuções e mortes decorrentes de tortura; Capítulo 12 - Desaparecimentos forçados.

4 Foram elaborados um relatório principal da Comissão Nacional da Verdade contento três volumes. Os três volumes estão assim distribuídos, em temos quantitativos: volume I (976 páginas); volume II (416 páginas); volume III (1996 páginas), totalizando 3388 páginas. Pode-se observar que o trabalho de análise e mesmo críticas ao Relatório requerem um trabalho mais sistematizado, pois o volume de dados é exaustivo para a pesquisa qualitativa. A pesquisa qualitativa mostra-se mais eficiente para uma análise temática dos dados. É claro que não se pode descartar uma pesquisa quantitativa, pois poderíamos tabular dados, o que o tornaria uma pesquisa mais esclarecedora. 0 método mais eficiente é tentar aliar os dados quantitativos com uma análise qualitativa, no sentido de fazer um estudo mais aprofundado. Isso vai permitir aos cientistas sociais um trabalho bem esclarecedor da história recente do Brasil.

5 Tabela produzida a partir do Relatório e dados disponíveis no site da Comissão Nacional da Verdade no Brasil, que pode ser encontrado através do seguinte endereço eletrônico: www. cnv.gov.br.

6 Para Candau (2012), a imaginação faz parte da memória humana; consiste em tudo o que vivemos e o que imaginamos ter vivido. 0 relato sobre a memória é sempre uma construção carregada de subjetividade, nunca pode ser considerado como um retrato fiel da realidade. A lembrança fiel é algo muito raro ou praticamente impossível.

7 Existe sempre um imaginário individual que criamos para dar significado as nossas ações e desejos, que são forjados em meio a uma coletividade.

8 Existem lugares consagrados de memória coletiva, onde se apoiam registros mais concretos e que podem aparecer mais visíveis. Os suportes das diferentes representações da memória devem constituir um patrimônio da humanidade, cabe aos arquivos, museus e demais órgãos de circulação da cultura guardar esses vestígios para que as gerações futuras tenham uma noção do que realmente aconteceu, de forma mais imparcial possível.

9 O que se define como memória subterrânea, pode comportar dimensões das memórias traumatizantes, que permaneceram por muito tempo ocultas ou mesmo censuradas.

10 Indiretamente isso já sugere certa consciência das barbaridades que foram realizadas, na época, deixando também uma suspeita no ar sobre a existência da expectativa de eventual impunidade.

$11 \mathrm{Na}$ articulação entre Memória e Perdão se pode compreender a dinâmica de conservação e mudança necessária para se pensar a evolução dos Direitos Humanos e consequentemente da sociedade. Por isso a contribuição de Ost pode ser de grande importância para se compreender esse processo de reconstrução da memória num contexto onde a responsabilização penal sobre os crimes cometidos no regime militar foi afastada e mesmo assim se busca a valorização dos Direitos Humanos através da construção de uma CNV. 
12 François Ost faz a distinção entre anistia menor ou das penas (penal) e aquela que o autor denomina de anistia maior ou dos fatos, bem assim da vinculação ou da desvinculação de uma relação à outra. Ost registra a profunda controvérsia existente sobre o tema. Paul Ricoeur: Todos os delitos do esquecimento estão contidos nessa pretensão incrível a apagar todos os vestígios das discórdias públicas. É nesse sentido que a anistia é o contrário do perdão, pois este, como ressaltaremos, exige memória.

13 Obviamente que aqui não se trata de se deparar com o passado no futuro, mas de estar diante de condições equivalentes contextualizadas no presente. Por isso é preciso romper com as condições de dominação e relação de poder que possibilitaram em tempos passados certos tipos de violações. 0 não enfrentamento disso, pode permitir problemas antigos de dominação e autoritarismo através de novas formas multifacetadas e disfarçadas.

\section{REFERÊNCIAS}

AGAMBEN, Giorgio. Homo Sacer: o poder soberano e a vida nua. Belo Horizonte: Editora UFMG, 2004.

BAUMAN, Zygmunt. Modernidade líquida. Tradução de Plinio Dentzien, Rio de Janeiro: Jorge Zahar, 2001.

BACHELARD, Gaston. A intuição do instante. Campinas: Verus, 2007.

BRASIL. Comissão Nacional da Verdade: relatório -Brasília: CNV, 2014. v. I. Disponível em: < http://www.cnv.gov.br/images/pdf/relatorio/volume_1_digital.pdf>. Acesso em: 5 set. 2017.

BRASIL. Comissão Nacional da Verdade: relatório: textos Temáticos. Brasília: CNV, 2014.v. II. Disponível em: <http://www.cnv.gov.br/images/pdf/ relatorio/volume_1_digital.pdf>. Acesso em: 5 set. 2017.

BRASIL. Comissão Nacional da Verdade: relatório: mortos e desaparecidos políticos. Brasília: CNV, 2014. v. III. Disponível em: <http://www.cnv.gov.br/ images/pdf/relatorio/volume_1_digital.pdf $>$. Acesso em: 5 set. 2017.

BRASIL. COMISSÃO NACIONAL DA VERDADE. Disponível em: <http://www. cnv.gov.br/institucional-acesso-informacao/a-cnv.html >. Acesso em: 3 set. 2017.

BRASIL. Lei no 6.683, de 28 de agosto de 1979. Disponível em: <http:// www.planalto.gov.br/ccivil_03/leis/L6683.htm>. Acesso em: 5 ago. 2017. 
BRASIL. Lei no 12.528, de 18 de novembro de 2011. Disponível em: <http://www.planalto.gov.br/ccivil_03/_ato2011-2014/2011/lei/l12528. htm>. Acesso em: 14 jul. 2017.

BRASIL. Decreto no 7.919, de 14 de fevereiro de 2013. Disponível em: < https://www.planalto.gov.br/ccivil_03/_ato2011-2014/2013/Decreto/D7919. htm>. Acesso em: 23 jul. 2017.

CANABARRO, Ivo. Caminhos da Comissão Nacional da Verdade (CNV): memórias em construção. Sequência, Florianópolis, v. 35, n. 69, p. 115-134, 2014.

CARNIO, Henrique Garbellini; GUERRA FILHO, Willis Santiago; PEREIRA, Joaquim Eduardo. Proposta de uma teoria político-jurídica: a relação entre o direito e o poder em sua articulação com a política e a violência. Revista de Direitos e Garantias Fundamentais, Vitória, v. 18, n. 1, p. 113-132, jan./abr. Disponpivel em: <https://doi.org/10.18759/rdgf.v18i1.854>. Acesso em: 10 nov. 2017.

CARVALHO, Maria Elizete Guimarães; RODRIGUES DOS SANTOS, Auristela; PESSOA, Ana Danielly Leite B. A educação em direitos humanos para a efetivação do direito à memória e à verdade. Revista Interdisciplinar de Direitos Humanos, Bauru, v. 5, n. 1, p. 207-224, 2017.

CAUDAU, Joel. Memória e identidade. São Paulo: Contexto, 2012.

FOUCAULT, Michel. Microfísica do poder. 26 ed. São Paulo: Graal, 2008.

FLORES, Luís Gustavo Gomes; SCHWARTZ, Germano. Direito como controle do Tempo (ou como controle temporal do Direito): a quem o abril despedaçou. In: ROCHA, Leonel Severo; DUARTE, Francisco Carlos. A construção sociojurídica do tempo: teoria do direito e do processo. Curitiba: Juruá, 2012.

GAGNEBIN, Jeanne Marie. 0 preço de uma reconciliação extorquida. In: TELLES, E.; SAFATLE, V. (Org.). 0 que resta da ditadura. São Paulo: Boitempo, 2010.

. Verdade e Memória do Passado. Projeto História: Revista do Programa de Estudos Pós-Graduados de História, São Paulo, v. 17, 1998. Dispo- 
nível em: <https://revistas.pucsp.br/index.php/revph/article/view/11147> Acesso em: 16 nov. 2018.

HALL, Stuart. A identidade cultural na pós-modernidade. São Paulo: DP\&A Editora, 2001.

HALBWACHS, Maurice. A memória coletiva. São Paulo: Centauro, 2004.

LE GOFF, Jacques. História em memória. Campinas, SP: Editora da UNICAMP, 1996.

KLEIN, Étienne. 0 tempo. Lisboa: Instituto Piaget, 1995.

LUHMANN, Niklas. Confianza. Barcelona/España: Anthropos; México: Universidad Iberoamericana; Santiago de Chile: Instituto de Sociología. Pontificia Universidad Católica de Chile, 1996.

Sociologia do Direito I. Tradução de Gustavo Bayer. Rio de Janeiro: Tempo Brasileiro, 1983.

MATURANA, Humberto. 0 que se observa depende do observador. In: THOMPSON, W. I. (Org.). GAIA: uma teoria do conhecimento. São Paulo: Editora Gaia, 2000. p. 61.

NORA, Pierre. Entre memória e história: a problemática dos lugares. Revista Projeto História, São Paulo, n. 10, p. 7-28, 1993.

OST, François. 0 tempo do direito. Lisboa: Instituto Piaget, 1999.

POLLACK, Michel. Memória, Esquecimento, Silêncio. Revista Estudos Históricos - FGV, Rio de Janeiro, v. 2, n. 3, p. 3-15, 1989. Disponível em: <http:// bibliotecadigital.fgv.br/ojs/index.php/reh/article/view/2278 >. Acessado em 03, set. 2017.

ROCHA, Leonel Severo. Epistemologia jurídica e democracia. 2. ed. São Leopoldo: Editora UNISINOS, 2003. 
. A construção do tempo pelo direito. In: ROCHA, Leonel Severo; STRECK, Lênio Luiz. Anuário do Programa de Pós-Graduação em Direito: Mestrado e Doutorado, Anuário/2003. São Leopoldo: UNISINOS, 2004.

Recebido em: 16-11-17

Aprovado em: 26-11-2018

\section{Luís Gustavo Gomes Flores}

Pós-Doutor, doutor e mestre em Direito Público pela Universidade do Vale do Rio dos Sinos (UNISINOS); professor do Programa de Pós Graduação em Direitos Humanos da Universidade Regional do Noroeste do Estado do Rio Grande do Sul; titular do projeto de pesquisa Desenvolvimento Humano, Transformações Sociais e Resiliência do Direito. E-mail: gustavogf7@gmail.com

\section{Ivo dos Santos Canabarro}

Pós-Doutor em história social pela Universidade Federal Fluminense (UFF); doutor em História Social pela UFF e Universidade de Paris III; professor ajunto II da Universidade Regional do Noroeste do Estado do Rio Grande do Sul (UNIJUÍ), atuando na Graduação de História presencial e EAD e no Programa de Pós-Graduação Stricto Sensu em Direito. E-mail: ivo.canabarro@unijui.edu.br

Universidade Regional do Noroeste do Estado do Rio Grande do Sul (UNIJUÍ). Programa de Pós-Graduação em Direito. Rua do Comércio, 3000, Bairro Universitário. CEP: 98700-000 